A MORTE COMO TRANSFORMAÇÃO:UMA APROXIMAÇÃO ENTRE DOM QUIXOTE E AÉTICA DE ESPINOSA

Giselle Cristina Gonçalves Migliari.

\section{PROÊMIO SOBRE A INTERPRETAÇÃO DA NATUREZA - FRANCIS BACON}

Tradução de Homero Santiago.

\section{RESENHA: ARTE E IMANÊNCIA: UM BOM ENCONTRO ENTRE}

ESPINOSA E VERMEER

Marcos Ferreira de Paula

RESENHA: A UNIDADE DO CORPO E DA MENTE: AFETOS, AÇÕES E

PAIXÕES EM ESPINOSA

Bruno D’Ambros

NOTÍCIAS

INSTRUÇÕES PARA OS AUTORES.

CONTENTS.

\section{ENTRE SERVIDÃO E LIBERDADE*}

Homero Santiago**

Resumo: Nosso propósito é delimitar um campo problemático que, na falta de melhor designação, pode-se dizer situado entre servidão e liberdade. É nesse terreno que tais categorias, que não devem ser tomadas como absolutas, podem assumir um sentido concreto, vinculado às variadas formas como os homens buscam a sua felicidade, umas vezes com êxito, outras com grande fracasso.

Palavras-chave: servidão, liberdade, transição, Espinosa, Pascal.

"É necessário conhecer tanto a potência quanto a impotência de nossa natureza." Espinosa 3, IV, prop. 17, esc.

"É ao nível de cada tentativa que se avaliam a capacidade de resistência ou, ao contrário, a submissão a um controle."

Deleuze 1, p. 218

Entre servidão e liberdade. Todas as nossas questões residem sob essa preposição que delimita um espaço de transição, movimentação entre duas categorias algo dúbias, equívocas, precisamente porque termos extremos de que lançamos mão mais por conveniência que entendimento. A tarefa que nos toca é desvendar um pouco o que acontece, o que se pode e o que não se pode entre os dois.

* Trata-se do prefácio de uma tese de livre-docência, que porta o mesmo título, apresentada ao Departamento de Filosofia da USP e defendida em 2012; daí nos permitirmos aqui e ali a remissão, sem maiores esclarecimentos, a alguns textos de nossa autoria.

** Professor do Departamento de Filosofia da USP. 
Postas as coisas assim, a lembrança de Pascal faz-se logo irresistível, pois como ninguém explicitou ele a necessidade de levar a sério o meio, aquilo que um intérprete denominou o "entre-dois". Com efeito, a crer nas análises de Henri Gouhier (4, p. 60 e seg.) das considerações de suas pesquisas sobre o vácuo até as preocupações apologéticas, Pascal serve-se de um esquema triádico em que o entre-dois é um elemento tão importante quanto os extremos. Modo de pensar, de analisar que surge com inigualáveis clareza e profundidade no célebre pensamento sobre a "desproporção" de um homem situado entre os dois abismos que lhe foram dados pela natureza (cf. Pascal 8, frag. 199). Mas esse esquema de pensamento funciona ainda, e talvez devamos dizer que funciona primordialmente, como um esquema para a ação, preparando o lugar da intervenção apologética. É entre uma coisa e outra que tudo se passa, e dessa perspectiva o meio é não só tão importante quanto os extremos como também se salienta sobre eles. É o reconhecimento das contrariedades, e portanto o reconhecimento do entre-dois como condição humana, que abre a apresentação do projeto apologético em Port-Royal, fornecendolhe o ponto de partida (idem, frag. 149); igualmente, é a convicção de que se precisa alcançar o meio que indica o tom apropriado ao discurso, nem muito alto nem muito baixo (idem, frag. 130).

O meio, para Pascal, assume tamanha relevância porque é nele que se dá a verdadeira conversão, a verdadeira transformação, possível exatamente por não estarmos afundados em nenhum dos abismos, convivendo sem trégua com ambos. Estamos entre extremos, é aí que o pensamento tem de se virar para entender o que somos e poder agir sobre o que seremos. Longe de constituir um campo estático, é lugar de passagens e mudanças. O que se revela cabalmente pelo termo que Pascal selecionou para nomear o maço integrado pelo pensamento sobre a desproporção humana: Transição. Palavra a ser frisada, pois que remete ao núcleo de uma problemática ética da maior importância e que não é exclusividade pascaliana. No essencial, reconhecemo-la também em Espinosa - o que demonstra de uma vez por todas que não é mister esposar o credo do jansenista para reconhecer que ele toca um problema real e de grande profundidade acerca de nossa natureza.

\section{$* * *$}

A ideia de transição é fundamental para o projeto ético espinosano e vincula-se à questão dos variáveis graus de perfeição ou potência de nossa natureza. $\mathrm{O}$ verbo transire e o substantivo transitio conhecem um uso frequente nas partes III-V da Ética, em contextos relevantes (cf. Gueret, Robinet, Tombeur 5). Os afetos primordiais de alegria e tristeza são transitiones entre graus diversos de perfeição; e nesse sentido todo afeto é passagem, transição; a inteira vida ganha a forma de incessante trânsito para lá e para cá, a ponto de Espinosa afirmar peremptoriamente que "vivemos em contínua variação" (Espinosa 3, V, prop. 39, esc.). Quer dizer, em nossa vida afetiva tudo é questão de graus, proporções e correlações, aumentos e diminuições; ela desconhece estados, ou não os conhece senão anomalamente, patologicamente. A transição constitui o fundo de nosso ser. Num trecho da Ética em que insiste que alegria e tristeza não são coisas nem entes, nem a própria perfeição nem a própria imperfeição, mas ambas transitiones, Espinosa lança mão de uma fórmula elucidativa: o afeto de tristeza, ele diz, não é senão um ato de passagem, um actus transiendi (idem, III, def. dos afetos, 3). Analogamente, digamos que o nosso ser é um esse transiendi. Invariavelmente posto no meio, sempre entre dois pontos. E não poderia ser diferente, uma vez que se radica todo ele no conatus e em acta transiendi; uma vez que é desejo. Nosso ser, nossa essência é esse complexo que reúne "todos os esforços, todos os impulsos, apetites e volições do homem, que variam de acordo com a sua variável constituição" (idem, III, def. dos afetos, 1). 
Desejo é intrinsecamente movimento. É a força motriz que subjaz nossas passagens e inclui ainda a consciência delas. Não por acaso, é nele que os problemas desvelados pelo conceito de superstição, como alhures apresentado (cf. Santiago 12), encontram toda a sua amplitude, sua plena significação, fincados como estão na própria constituição de nosso ser, na própria estrutura do nosso desejo. Tudo se decide aí, mas não de maneira simplória. É necessário conferir o devido peso à brevíssima descrição da condição humana que Espinosa dá no apêndice da Ética I; e sem esquecer que, se lá ela serve de fundamento à dedução da superstição, igualmente poderia servir à dedução da liberdade, pois é a partir da mesma condição que se vai numa ou noutra direção. "Todos os homens nascem ignorantes das causas das coisas e todos têm o apetite de buscar o que lhes é útil, sendo disto cônscios." Há de origem uma coisa finita, um apetite, um esse transiendi ao qual se ajunta o saber, a apercepção, a consciência de seus movimentos, de suas transições. Somos cônscios disso, portanto desejantes. Todavia, em simultâneo a clausula da ignorância nativa determina que não somos cônscios de algo, das causas das coisas; principalmente, temos de dizer em respeito ao uso do fundamento no apêndice, não somos cônscios das causas de nossos desejos. Junto à consciência, dá-se uma região do não-sabido, da não-consciência ou inconsciência, que põe todo o enigma de nosso ser desejante em face do mundo. Por que quero isso e não aquilo? Porque me surge como útil, decerto. Porém, sabe-se, não desejamos algo porque é útil; pelo contrário, é porque desejamos que algo nos surge como útil. Mas por que primeiramente queremos a coisa que, num segundo momento, aparecerá como útil? Certamente cada um de nossos impulsos tem causa; não obstante, em regra, a ignoramos. Ao querer, uma pessoa normalmente sabe que quer e sabe o que quer, mas quase nunca sabe por que quer o que quer. Trata-se de uma ignorância que, em algum grau, acompanha todo querer e que se explica pelo enraizamento profundo desse querer no ser mais íntimo de cada um; o qual por seu turno está enraizado num mundo que o ultrapassa infinitamente, sendo imperscrutável em todos os seus meandros.

Somos ignorantes $e$ desejantes. Eis um dado crucial para a complexidade de nosso ser, em sua totalidade. Fossemos só ignorantes, estaríamos próximos da vida animal, quiçá da mineral; pois com certo abuso podemos dizer que um verme bem como uma pedra igualmente ignoram; só que justo por não desejarem não produzem superstição. Fossemos só desejantes, nada ignorássemos, o verdadeiro seria para nós uma sorte de instinto; jamais se desejaria isso ou aquilo, mas só o realmente melhor, com base firme no conhecimento das causas. Nada disso. A humanidade depende inextricavelmente da amarração górdia, no ser do homem, de ignorância e desejo, certa ignorância e certa inconsciência combinadas com certo saber e certa consciência em variada proporção mas sempre indissociáveis. Trata-se de um nexo capital na Ética e ao qual pouco se chama a atenção, talvez devido ao receio, de resto compreensível, do uso da palavra "consciência". Nesse caso, basta não substancializá-la, não a querer remetendo a uma interioridade. Também a consciência, aquela envolvida no desejo, é um fenômeno do meio, que relata algo de nossas relações com o real e depende igualmente de uma graduação. ${ }^{1}$

Como ignorância e desejo não se separam, inconsciência e consciência também não. E por isso, ainda, gostaríamos aqui de conceber servidão e liberdade como, em certo sentido, inseparáveis. Sentido que provavelmente não esgota as noções, mas que não deixa de exprimir uma verdade. É preciso desontologizar, desestatificar, por assim dizer, essas categorias; restituir-lhes o significado que pode emergir a partir do entre, isto é, do campo das transições e da perpétua variação. Um mesmo movimento pode assumir direções opostas, um mesmo ser desejante pode mover-se numa ou noutra direção, e com os termos servidão e liberdade 
designamos as correlações dinâmicas desse movimento; jamais coisas ou entes ou estados absolutos. Tomá-los à guisa de absolutos é erro simétrico a crer que as noções que usamos para pensar as coisas possam encontrar seus correspondentes nas próprias coisas. Servidão e liberdade são palavras de que nos servimos para indicar certa predominância na direção assumida por um desejo, portanto certa estruturação momentânea de um ser, conforme prevaleça ou o rebaixamento ou o aumento de sua potência. Entre um e outro há diferença decisiva de grau, proporção, não de natureza. Tanto servidão quanto liberdade radicam-se na mesma busca do útil, na mesma natureza desejante. Ex natura nostra libertas \& servitudo: é o que nos obriga a pensar ambas, conjuntamente, como parte de nós e sem exclusivismos fáceis.

\section{$* * *$}

Tudo depende do desejo, da natureza em geral e da nossa natureza em particular. Só que essa certeza não pode fazer as vezes de panaceia. O desejo é um terreno de tensões; campo em que as partidas são jogadas, as apostas são feitas, sem ganhos nem perdas garantidos. Ao contrário do que vez ou outra parece imaginar um correntio para o qual a mera liberação do desejo seria o visto de entrada para a melhor das vidas, Deleuze e Guattari perceberam bem que o compromisso com a imanência não salva ninguém de antemão, não afiança a liberdade mais que a servidão. Os campos de concentração, as piores formas de opressão foram produzidos pelo mesmo desejo que movimentou as revoluções e inventou tenazes formas de resistência. Naturalmente, sempre. E daí declararem ser o problema maior da filosofia política entender por que, como reconhecera Espinosa, "os homens combatem por sua servidão como se se tratasse da sua salvação". ${ }^{2}$

Na situação torta aí identificada vem uma mostra expressiva de quantas agruras o nosso desejo é capaz de reservar-nos. Pensando em nossa tese, está aí um efeito maior da superstição. O que é superstição? É a servidão tornada sistema. Não é um preconceito nem um conjunto de preconceitos, não é redutível a crendices ou superstições, não é falsa consciência nem ignorância, não é tristeza nem medo. Superstição é o nome que se pode dar ao que emerge a partir do momento em que tudo isso se sistematiza; ao que resulta da elevação desses elementos a uma forma de sistema que explica, estrutura, organiza o real, incluindo aí nós mesmos, nossos desejos, nossa vida. Superstição é sistema da servidão. O seu segredo é a passagem do ocasional e fortuito ao necessário, sistêmico, estrutural. Transformação qualitativa dos elementos de nossa condição que a superstição consegue precisamente pelo desprezo à variação, pela rareação das transições, pela supressão do meio; no limite, ela acaba com a história para que seu império seja o mais perfeito, o mais perene possível. Sua forma acabada é o fatalismo, a ser compreendido no sentido preciso de mistificação das tensões, enrijecimento do mundo, esgotamento do novo, ontologização da liberdade e felicidade (só no além, o paraíso, o pós-revolução, o pósreformas), da servidão e infelicidade (tudo neste mundo, nesta condição hodierna), da consciência (um dado substancial), da ignorância (que ou não poderia ser minorada ou, pelo contrário, seria facilmente superável). Gostaríamos de compreender o termo superstição nesse sentido amplo, que permita pensar da "ordem da vida comum" de que fala Espinosa até os campos nazistas, a obediência cega, o ódio ao diferente (cf. Santiago 10 e 13). Mas igualmente pensar os meios para seu enfrentamento. Reconhecido o seu segredo - o amortecimento da variação - e seu efeito maior - o fatalismo -, o primeiro gesto de luta só pode consistir, sem ilusões, no restabelecimento da variação, no retorno ao meio e às tensões, de modo tal que até o reencontro da servidão natural, isto é, restituída a seu lugar no vai e vem de nossa potência, já seja um ganho. 
Ora, os homens lutam por sua servidão como se lutassem por sua liberdade. Mecanismo terrível, sobretudo por sua eficácia. Não se pode negá-lo. Porém, cabe a pergunta: será essa a única dimensão possível para avaliar a situação? A ênfase sobre um aspecto não precisa ser exclusivista a ponto de impossibilitar todas as outras perspectivas. Certo que os homens, no final das contas, combatem pela servidão. Mas só o pior fatalista concebe, geralmente porque lhe interessa, contas findas. Para nós, elas nunca estão terminadas. O que mais interessa é o aventuroso in-fieri do cálculo; e nesse entanto os homens lutam efetivamente pela liberdade, mesmo que não por uma liberdade efetiva. É uma distinção importante, similar àquela que encontramos na Ética entre dizer que todos buscam o útil, efetivamente, e começar a se preocupar a certa altura em indagar o que é "efetivamente útil (revera utile)" (Espinosa 3, IV, prop. 18, esc.). Seja como for, notável é que em nenhum momento Espinosa retire da base da virtude o mesmo esforço pelo útil, quer se movimente através da liberdade, quer descambe pela servidão.

Em suma, queremos aqui frisar que, tão necessário quanto afirmar que os homens em certas circunstâncias produzem servidão como se buscassem a liberdade, é ver que nas mesmas circunstâncias eles buscam sua liberdade mesmo que produzindo a servidão. E nenhuma das pontas pode ser abandonada, ao custo de entrarmos no terreno de uma meia-sabedoria (denunciada por Pascal e de que logo falaremos) que periga acantoar-se numa unilateralidade, numa unidimensionalidade tão perversa quanto a própria superstição ao abraçar, por vias outras, o sentimento da fatalidade, um senso excepcionalmente aguçado para ver tudo de um só ponto de vista.

Nem otimismo nem pessimismo, só pensar sem cessão à unilateralidade, não importa qual. E voltar a acreditar, reencontrar uma fé que a fatalidade, venha de onde vier, tem o dom de roubar-nos.
O traço mais ousado e fascinante da apologética de Pascal é também o mais problemático. Apologia e jansenismo seriam compatíveis? O empenho, no caso da salvação, serve para algo? Tomemos uma passagem dos Escritos sobre a graça. De um lado, está a "opinião apavorante" dos calvinistas, "injuriosa a Deus e insuportável aos homens", que estabelece uma vontade divina absoluta que não leva em conta a previsão nem de méritos nem de pecados; de outro está o erro inverso dos molinistas, que excluem a intervenção de qualquer vontade absoluta no que se refere a salvação ou perdição, que ficam portanto na inteira dependência da vontade humana (Pascal 7, pp. 312-313). Entre esses extremos Pascal se equilibra; nem dados lançados de uma vez por todas nem um xadrez em que a vitória só depende do mérito do jogador. E não é nada fácil manter o equilíbrio tendo de permanecer fiel à predestinação do Agostinho lido por Jansênio. Como a corda bamba se resolve teologicamente e quais suas implicações para o jansenismo pascaliano, pouco interessa aqui (para uma discussão do problema, ver Gouhier 4, p. 159 e seg). Importante é que daí resulte a própria possibilidade e pertinência da apologia, isto é, do empenho humano em dar bom rumo a coisas que não estão totalmente em seu poder e tampouco fogem completamente a sua alçada, ainda que por ignorância. Ouçamos a conclusão de Pascal. "Que todos os homens do mundo estejam obrigados, sob pena de danação eterna e pecado contra o Espírito Santo irremissível neste mundo e no outro, a crer que estão nesse pequeno número de Eleitos para a salvação dos quais J.C. morreu e a ter o mesmo pensamento de cada um dos homens que vivem sobre a terra, por mais que alguns sejam maus e ímpios, enquanto lhes restar um momento de vida, deixando o discernimento dos Eleitos e dos reprovados no impenetrável segredo de Deus.” (apud Gouhier 4, p. 161) 
Por isso a apologia tem lugar; mais, por isso ela constitui uma obrigação e uma tarefa. Dificilmente haverá melhor forma de lidar com uma determinação inapreensível, com um mundo que nos ultrapassa, dado antes de chegarmos e que continuará quando partirmos. Estamos obrigados a crer em nós, abraçando o pensamento da terra e deixando o juízo final ao arbítrio do próprio juiz. A apologia precisa restaurar o campo de tensões, repor contrariedades e paradoxos que não podem restar camuflados, resgatar o antagonismo entre altos e baixos, descobrir o terreno certo em que agir. Só assim ela pode ter algum sentido, isto é, alguma eficácia, ainda que não haja garantias de êxito.

Para tanto, muito significativamente, um de seus primeiros gestos é a revisão dos pontos de vista imperantes, lançando em suspeita os inteligentes que caçoam e desacreditam do mundo e dos homens. Ora, sob certa perspectiva, as opiniões do "povo" são "muito sãs"; por exemplo, "ter escolhido o divertimento, e a caça de preferência à presa". "Os meio-sábios zombam disso e triunfam mostrando a esse respeito a loucura do mundo, mas por uma razão que eles não penetram" (Pascal 8, frag. 101). Raciocínio idêntico ao que encontramos estendido nas conhecidas linhas sobre o divertimento. "Eis tudo que os homens puderam inventar para se tornar felizes, e aqueles que, a respeito disso, bancam os filósofos e acreditam que o mundo é bem pouco razoável se passa o dia a correr atrás de uma lebre que não gostariam de ter comprado, não conhecem nada da nossa natureza. Essa lebre não nos garantiria contra a visão da morte e das misérias que nos desviam dela, mas a caça sim, nos garante.” (idem, frag. 136)

Os meio-sábios, sublinhemos, "não conhecem nada de nossa natureza". Noutras palavras, a meia-sabedoria é uma ignorância total. Que seja posta de lado a meia-sabedoria, portanto, em benefício de uma sabedoria do meio que pode ao menos, como faz Pascal, discernir um aspecto verdadeiramente imanente do desejo pelo bem, pelo útil; não tanto nos resultados quanto em sua própria atividade; menos a presa que a perseguição, menos o prêmio que o jogo - pensando na interpretação de Masoch feita por Deleuze (cf. Santiago 9), vem a tentação até de dizer: menos o gozo ou o prazer que o desenvolvimento produtivo de um campo imanente do desejo. Pascal é grande porque a apologia é como sua caçada, a corrida atrás de uma lebre, a graça, que só pertence a Deus. Não obstante, ele nisso se empenha com todas as suas forças. Não apenas sugere a razoabilidade da aposta, como ele mesmo aposta, equilibrando-se, na própria incerteza; à apologética incumbe, em primeiríssimo lugar, fazer como o povo faz todo dia, sanamente: "trabalhar pelo incerto, ir pelo mar, caminhar sobre uma prancha" (Pascal 8, frag. 101).

Dita aposta nos dá um modelo, não único mas excepcional, de uma atitude valente contra o fatalismo e os extremos absolutos. Similar àquela que gostaríamos de discernir ao falar de possível (cf. Santiago 11). Trabalhar pelo incerto, com a certeza de que esse trabalho vale a pena. Um ato de fé? Sim. Por que não? Tem-se fé em tantas coisas, por que não assumir a mais importante? Uma crença no mundo como aquela que Deleuze dizia ser "o que mais nos falta" (Deleuze 1, p. 218), e cuja redescoberta pensamos constituir uma das tarefas mais urgentes da filosofia. Ou ainda, convicção em nossas possibilidades, como recentemente, pouco antes da morte e já certo de sua proximidade, cobrou o historiador Tony Judt: "Não precisamos acreditar que nossos objetivos estão destinados ao êxito. Mas precisamos ser capazes de crer neles" (Judt 6, p. 167).

Esse tipo de aposta, fé, crença, esperança, convicção, seja qual o nome se der a isso, é condição de toda virtude. E só há virtude no meio. 


\section{BETWEEN SERVITUDE AND FREEDOM}

Abstract: Our purpose is to define a problematic field that, in absence of a better description, can be situated between servitude and freedom. In this field, these categories should not be taken as absolutes, and they may assume a concrete sense, linked to the varied ways in which men seek happiness, sometimes successfully, sometimes with great failure.

Keywords: servitude, freedom, transition, Spinoza, Pascal.

\section{REFERÊNCIAS BIBLIOGRÁFICAS}

1. DELEUZE, G. “Controle e devir”. Entrevista a Toni Negri. In: Conversações. Trad. Peter Pál Pelbart. Rio de Janeiro, Ed. 34, 2000.

2. __ GUATTARI, F. O Anti-Édipo. Capitalismo e esquizofrenia 1. Trad. Luiz B. L. Orlandi. São Paulo, Ed. 34, 2010.

3. ESPINOSA, B. Ethica. In: Opera. Ed. Carl Gebhardt. Heidelberg, Carl Winters Universitætbuchhandlung, 1972, v. 2.

4. GOUHIER, H. Blaise Pascal. Conversão e apologética. Trad. Éricka Marie Itokazu e Homero Santiago. São Paulo, Discurso Editorial \& Paulus, 2005.

5. GUERET, M.; ROBINET, A.; TOMBEUR, P. Spinoza. Ethica. Concordances, index, liste de fréquences, tables comparatives. Louvain-la Neuve, CETEDOC, 1979.

6. JUDT, T. O mal ronda a terra. Um tratado sobre as insatisfações do presente. Trad. Celso Nogueira. Rio de Janeiro, Objetiva, 2011.

7. PASCAL, B. Euvres complètes. Ed. Louis Lafuma. Paris, Seuil, 1963.

8. . Pensamentos. Trad. Mario Laranjeira. São Paulo, Martins Fontes, 2001.

9. SANTIAGO, H. "Deleuze leitor de Masoch: da sintomatologia à ética". Comunicação apresentada no colóquio "Deleuze leitor dos modernos", Departamento de Filosofia-USP, agosto de 2010. Inédito.

10. _ . "Os excessos da identidade. Bento XVI e a questão da tolerância". Lua Nova. Revista de cultura e política, São Paulo, no 74, 2008. Disponível: http://www.scielo.br/pdf/ln/n74/08.pdf
11 . "Por uma teoria espinosana do possível". Revista Conatus, Fortaleza, no 9, 2011. Disponível: http://www.benedictusdespinoza.pro.br/Revista_ Conatus_V5N9_Jul_2011_Artigo_Homero_Santiago.pdf

12. ___ . "Superstição e ordem moral do mundo". In: Martins, A. O mais potente dos afetos. Spinoza e Nietzsche. São Paulo, WMF Martins Fontes, 2009.

13.

"Tem-se a polícia que se merece". Cadernos de ética e filosofia política, São Paulo, no 9, 2006. Disponível: http://www.fflch.usp.br/df/cefp/Cefp9/ santiago.pdf

\section{NOTAS:}

1. Deus, as coisas, nosso próprio ser, não poderiam ser diversos; portanto, o que é crucial mudar em vista da felicidade é a nossa relação com o que existe; se há uma lição a tirar da noção espinosana de emendatio, esta é a principal. Conforme a quinta parte da Ética, é o que faz toda a diferença na determinação da superioridade do sábio perante o ignorante. Este é agitado pelas causas exteriores, desconhece o contentamento e é "quase ínscio de si, de Deus e das coisas"; em troca, aquele conhece o contentamento, pouco se perturba e é "cônscio de si, de Deus e das coisas" (Espinosa 3, V, prop. 42, esc.). Frise-se que a diferença é de grau, não absoluta. Nem o ignorante é completamente inconsciente (Espinosa diz "quase") nem o sábio é completamente consciente (diz-se que ele é "dificilmente" perturbado, não que nunca o seja). A graduação é ainda mais clara quando o filósofo nos explica que aquele cujo corpo é dependente do exterior, como o de um bebê, tem uma mente que é "quase nada (nihil fere) cônscia nem de si, nem de Deus, nem das coisas"; já quem possui o corpo apto ao múltiplo tem uma mente "muito cônscia de si e de Deus e das coisas" (idem, V, prop. 39).

2. Ver Deleuze \& Guattari 2, p. 46: "Há tão somente o desejo e o social, e nada mais. Mesmo as mais repressivas e mortíferas formas da reprodução social são produzidas pelo desejo, na organização que dele deriva sob tal ou qual condição (...). Eis por que o problema fundamental da filosofia política é ainda aquele que Espinosa soube levantar (e que Reich redescobriu): 'Por que os homens combatem por sua servidão como se se tratasse da sua salvação?'.” 